\title{
Ocorrência de Herminodes sp. (Lepidoptera: Noctuidae) em pupunheira nos estados do Acre e Rondônia, Brasil.
}

\author{
Marcílio José THOMAZINI ${ }^{1}$
}

\section{RESUMO}

É relatado a ocorrência de Herminodes sp. em plantas de pupunha na área experimental da Embrapa Acre, Rio Branco, AC e no Projeto Reca, Vila Nova Califórnia, RO, Brasil. São descritas as principais características deste inseto e os danos por ele causados. Este é o primeiro registro de lagartas do gênero Herminodes causando dano em pupunheiras nos estados do Acre e Rondônia.

PALAVRAS-CHAVE

Bactris gasipaes, inseto, lagarta, danos

\section{Occurrence of Herminodes sp. (Lepidoptera: Noctuidae) in peach palm in the states of Acre and Rondônia, Brazil.}

\begin{abstract}
Related herein is the occurrence of Herminodes sp. in peach palm plants at experimental area of Embrapa Acre, Rio Branco, AC and at Projeto Reca, Vila Nova California, RO, Brazil. The main characteristics of this insect and the damage it causes are described. This is the first record of Herminodes caterpillars damaging peach palm in the states of Acre and Rondônia.
\end{abstract}

KEY WORDS

Bactris gasipaes, insect, caterpillar, damage

A pupunha (Bactris gasipaes Kunth), é uma planta perene, nativa da Amazônia, que possui grande importância econômica para a região, sendo cultivada para produção de frutos e palmito, tanto em monocultivo como em sistemas agroflorestais.

São poucos os relatos sobre ocorrência de artrópodes causando dano as plantas desta palmeira, visto que o seu cultivo em escala comercial é recente. Assim, Couturier et al. (1991) descrevem o percevejo Leptoglossus lonchoides como o agente causal da queda dos frutos de pupunha em monocultivo na região de Manaus, AM.

Ronchi-Teles et al. (1992) citam várias espécies de insetos e ácaros ocorrendo em pupunha em Manaus, entre eles uma espécie não identificada de um lepidóptero do gênero Herminodes. Contudo, não houve uma descrição mais detalhada do inseto e dos danos causados.

Villachica (1996a) lista o ácaro das folhas (Retracus jobnstoni) como praga, podendo ocorrer no período mais seco, especialmente em viveiros.
Villachica (1996b) descreve que a pupunha pode ser atacada pelos coleópteros Rhynchophorus palmarum, vetor do nematóide Rhadinaphelenchus cocopbilus, causador do "anel vermelho do coco" e Metamasius bemipterus, que pode fazer galerias na base da raquis da inflorescência, debilitando-a e provocando a queda da inflorescência ou dos racemos.

Couturier et al. (1996) relatam diversos insetos e ácaros como pragas potenciais ocorrendo em pupunha na Amazônia peruana, entre eles está Rhamnocampa albistrigata (Noctuidae), espécie muito parecida com Gabara (Herminodes) insulsa que ocorre em dendê.

Vasquez et al. (2000) relatam a ocorrência em pupunha, na Amazônia peruana, de um curculionídeo, Dynamis nitidulis, causando danos similares a $R$. palmarum.

O objetivo deste trabalho é relatar a ocorrência e os danos do lepidóptero Herminodes sp. em plantios de pupunha nas regiões de Rio Branco, AC e Vila Nova Califórnia, RO. 


\section{ACTA AMAZONICA}

OCORRÊNCIA DE HERMINODES SP. (LEPIDOPTERA: NOCTUIDAE) EM PUPUNHEIRA NOS ESTADOS DO ACRE E RONDÔNIA, BRASIL.
As observações e coletas foram feitas de novembro de 2002 a janeiro de 2003 em áreas de plantios comerciais de pupunha consorciada com cupuaçu (Theobromagrandiflorum) e castanha-do-brasil (Bertbolletia excelsa), com cerca de 12 anos, no Projeto Reca (Reflorestamento Econômico Consorciado e Adensado), Vila Nova Califórnia, RO (entre as coordenadas

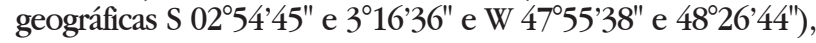
na divisa com o Estado do Acre, e no campo experimental da Embrapa Acre, em Rio Branco, AC (S 958'22" e W 67\%48'40"), em uma área de 0,5 ha de pupunha com 24 a 26 meses, predominantemente sem espinho, visando produção de palmito.

Foram coletadas lagartas e pupas, que foram trazidas para o Laboratório de Entomologia da Embrapa Acre. No laboratório $\left(25 \pm 2{ }^{\circ} \mathrm{C}, 60 \pm 10 \%\right.$ de umidade relativa e $12 \mathrm{~h}$ fotofase) as lagartas foram alimentadas com pedaços de palmito de pupunha até a formação das pupas. Posteriormente as pupas foram colocadas em recipientes para obtenção dos adultos.

Foram obtidos 59 exemplares adultos de uma mariposa da família Noctuidae identificada como Herminodes sp., pelo Dr. Vitor Becker, do Departamento de Zoologia, do Instituto de Ciências Biológicas/ Universidade de Brasília. Não houve emergência de nenhum parasitóide das lagartas trazidas do campo.

$O$ adulto é uma mariposa que mede, em média, 29,03 mm de envergadura (desvio padrão de 1,89 mm) e 14,29 mm de comprimento (desvio padrão de 1,64 mm). Possui coloração pardo-acinzentada, tendo as asas anteriores pequenas manchas escuras esparsas e uma coloração mais escurecida nos bordos. As asas posteriores são mais claras que as anteriores e possuem os bordos escurecidos (Figura 1A).

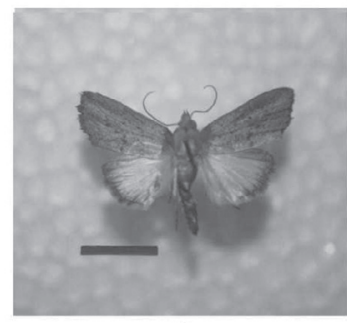

A

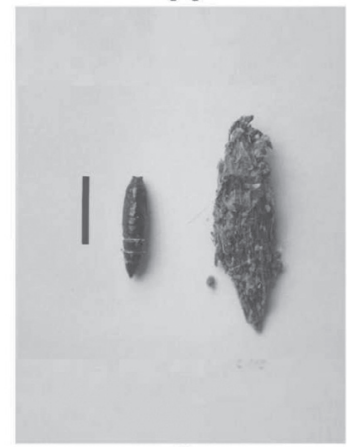

C

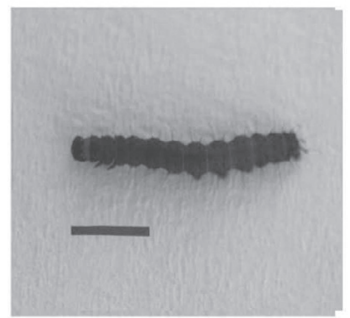

B

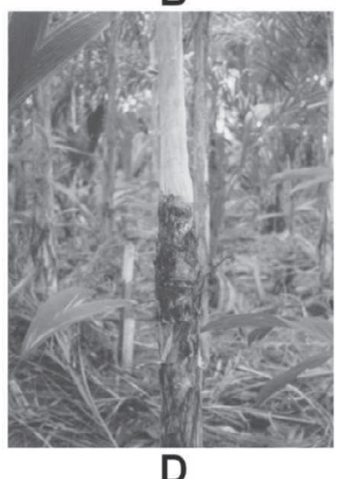

Figura 1 - Fases de desenvolvimento de Herminodes sp. e seus danos em plantas de pupunha em Rio Branco, AC. 2003. A. adulto, B. lagarta, C. pupa e casulo, D. danos no estipe. As barras medem $10 \mathrm{~mm}$ em $1 \mathrm{~A}-\mathrm{C}$
As lagartas, quando completamente desenvolvidas, medem, em média, 29,19 $\mathrm{mm}$ de comprimento (desvio padrão de $1,81 \mathrm{~mm}$ ). Possuem coloração marromavermelhada, com pelos esparsos sobre o corpo (Figura 1B). Empupam protegidas em casulos feitos com material retirado da planta. A pupa tem o comprimento médio de $15 \mathrm{~mm}$ (Figura 1C). Esses casulos ficam aderidos ao estipe ou a parte interna da folha, próximo a junção das mesmas com o tronco.

Com relação aos danos e sintomas, a lagarta se aloja na junção da bainha da folha com o estipe, na base do palmito, se alimentando nessa região da planta, que fica com o estipe rachado, deformado, podendo ocorrer acúmulo de água e apodrecimento, quebra do tronco e morte da planta (Figura 1D). A lagarta não penetra no interior do colmo e sua presença é notada também pela grande quantidade de fezes no local. Mais de uma lagarta pode ocorrer por folha.

Nos plantios do Projeto Reca o ataque não foi tão intenso quanto no plantio na Embrapa Acre, onde mais de 50\% das plantas apresentaram uma ou mais lagartas. No entanto, isso não significou perda proporcional de produção, pois pouco mais de $5 \%$ das plantas destaárea morreram em decorrência do ataque deste inseto. Este é o primeiro registro deste inseto causando dano em pupunha nos estados do Acre e Rondônia.

Acompanhamentos futuros serão realizados para determinar se este inseto poderá constituir uma nova praga para a cultura da pupunha na região.

\section{BIBLIOGRAFIA CITADA}

Couturier, G.; Clement, C.R.; Viana Filho, P. 1991. Leptoglossus lonchoides Allen (Heteroptera, Coreidae), causante de la caida de los frutos de Bactris gasipaes (Palmae) en la Amazonia Central. Turrialba, 41(3): 293-298.

Couturier, G.; Tanchiva, E.; Inga, H.; Vasquez, J.; Riva, R. 1996. Notas sobre los artrópodos que viven en el pijuayo (Bactris gasipaes H.B.K.: Palmae) en la Amazonia peruana. Revista Peruana de Entomologia, 39 (1-3): 133-142.

Ronchi-Teles, B.; Couturier, G.; Hamada, N. 1992. Insetos associados a pupunheira (Bactris gasipaes, Arecaceae) na região de Manaus, Am. In: Congresso Latino Americano de Zoologia, $12 \mathrm{e}$ Congresso Brasileiro de Zoologia, 19. Resumos. Sociedade Brasileira de Zoologia/UFPA/MPEG, Belém. p. 89-90.

Vasquez, J.; O’Brien, C.W.; Couturier, G. 2000. Dynamis nitidulis (Coleoptera: Curculionidae), nueva plaga del pejibaye. Manejo Integrado de Plagas, 58: 70-72.

Villachica, H. 1996a. Cultivo de pejuayo (Bactris gasipaes Kunth) para palmito en la Amazonia. TCA, Lima, Peru. 152 p.

Villachica, H. 1996b. Pijuayo. Bactris gasipaes H.B.K.. In: Villachica, H. (Ed). Frutales y hortalizas promisorios de la Amazonia. Tratado de Cooperacion Amazonica, TCA, Lima, Peru. p. 215-226. 